\title{
AVALIAÇÃO DO CRESCIMENTO DO ESTRATO ARBÓREO DE ÁREA DEGRADADA REVEGETADA À MARGEM DO RIO GRANDE, NA USINA HIDRELÉTRICA DE CAMARGOS, MG ${ }^{1}$
}

Wendy Carniello Ferreira² ${ }^{2}$ Soraya Alvarenga Botelho ${ }^{3}$, Antonio Claudio Davide ${ }^{3}$ José Márcio Rocha Faria ${ }^{4}$

\begin{abstract}
RESUMO - No presente trabalho foi analisado o crescimento de espécies arbóreas plantadas em um gradiente topográfico em área de empréstimo de terra para construção da barragem da UHE Camargos, MG. Para tanto, aos 155 meses após o plantio foram alocados três transectos no sentido do declive, com $15 \mathrm{~m}$ de largura e comprimento variável. Os transectos foram divididos em parcelas de 12 x $15 \mathrm{~m}$ para controle do gradiente topográfico. Os indivíduos com circunferência à altura do peito (DAP) $\geq 5 \mathrm{~cm}$ foram identificados e medidos no seu diâmetro e altura. A partir dos resultados, concluiu-se que, de modo geral, as espécies pioneiras apresentaram um ritmo de crescimento maior nos primeiros 58 meses e as climácicas, no período entre 58 e 155 meses. Houve efeito da compactação do solo e do gradiente topográfico sobre o crescimento das plantas.
\end{abstract}

Palavras-chave: Restauração, mata ciliar, silvicultura e espécies florestais nativas.

\section{GROWTH OF THE TREE STRATUM IN RESTORED AREA NEAR RIO GRANDE IN THE CAMARGOS HYDROELECTRIC PLANT, STATE OF MINAS GERAIS}

\begin{abstract}
The objective of this study was to analyze the growth of tree species planted in a topographic gradient in an area degraded for the construction of the dam of Camargos Hydroeletric plant, MG. At 155 months after planting, three transects following the slope, $15 \mathrm{~m}$ wide and variable length were allocated, subdivided in parcels of $12 \times 15 \mathrm{~m}$ along the topographic gradient. Plants with diameter at breast height $(D B H) \geq 5 \mathrm{~cm}$ were identified and measured (DBH and height). We concluded that, generally, the pioneer species showed a faster growth rhythm in the first 58 months and the climax species in the period of 58 to 155 months. Plant growth was affected by soil compactation and the effect of the topography gradient.
\end{abstract}

Keywords: Land restoration, riparian forest, silviculture and native forests species.

\section{INTRODUÇÃO}

Vários desafios precisam ser enfrentados para a recuperação de áreas degradadas. Um dos mais importantes é a adoção de técnicas de revegetação eficazes e adequadas às peculiaridades do local a ser recuperado. Na prática, entretanto, muitas vezes escolhem-se técnicas com base apenas em intuições e receitas, com a única finalidade de amenizar, em curto prazo, a depreciação estética da área. Além disso, muitas iniciativas passam, exclusivamente, pelo cumprimento das exigências legais.

A avaliação da extensão de áreas degradadas é um processo complexo, pois o conceito de solo degradado não está claramente definido. Após atividades que

\footnotetext{
${ }^{1}$ Recebido em 28.06.2006 e aceito para publicação em 18.12.2006.

${ }^{2}$ Programa de Pós-Graduação em Engenharia Florestal da Universidade Federal de Lavras. E-mail: <wcferreira_4@ $@$ hotmail.com>.

${ }_{3}^{3}$ Departamento de Ciências Florestais da UFLA. Bolsista CNPq. E-mail:<sbotelho@ufla.br; acdavide@ufla.br>.

${ }^{4}$ Departamento de Ciências Florestais da UFLA. E-mail:<jmfaria@ufla.br>.
} 
causam grandes distúrbios, como a mineração e em áreas de empréstimo para a construção de barragens e aterros, a caracterização torna-se óbvia, mas em áreas em que a degradação ocorre de forma lenta e gradual, como nas atividades agrícolas, a caracterização é mais difícil (DIAS e GRIFFITH, 1998).

Segundo Carpanezzi et al. (1990), um ecossistema degradado é aquele que após distúrbios, teve eliminados, com a vegetação, os seus meios de regeneração biótica. Seu retorno ao estado anterior pode não ocorrer ou ser bastante lento. Nesse caso, a ação antrópica é necessária para a sua regeneração em curto prazo.

A degradação das áreas de empréstimo consiste na remoção da vegetação original e na retirada da camada superficial do solo, expondo o horizonte $\mathrm{C}$ e causando compactação, perda de matéria orgânica e baixa disponibilidade de nutrientes, fazendo que o substrato resultante não permita o desenvolvimento da regeneração natural da vegetação. A degradação dessas áreas também resulta em efeitos deletérios sobre os mananciais hídricos e a fauna local.

O sucesso dos projetos de recuperação de áreas degradadas depende, entre outros fatores, da escolha correta das espécies vegetais. Decorrente do grande número de espécies e de suas complexas inter-relações e interações com o ambiente, a escolha será tanto mais correta quanto maior for o conhecimento pertinente a elas. Esse conhecimento se refere, basicamente, à auto-ecologia e ao comportamento silvicultural (FERREIRA, 2001). Entretanto, segundo Arato (2003), nem sempre é possível o retorno de um ecossistema degradado à sua condição original devido, entre outras causas, ao estado de degradação a que foi submetido.

O plantio de espécies arbóreas sob diversas condições edafoclimáticas e o monitoramento de seu desempenho por meio de medições periódicas são, portanto, importantes no sentido de fundamentar sua escolha e a melhor forma de plantá-las, principalmente em áreas degradadas (FERREIRA, 2001). É nesse contexto que este trabalho foi realizado, com o objetivo de analisar o crescimento de espécies arbóreas plantadas em diferentes gradientes topográficos em área degradada.

\section{MATERIAL E MÉTODOS}

\subsection{Descrição da área}

O levantamento foi realizado em um sítio situado a jusante da barragem da Usina Hidrelétrica de Camargos, à margem direita do rio Grande, em uma altitude média de $890 \mathrm{~m}$. O sítio localiza-se no Município de Itutinga, região fisiográfica Campo das Vertentes (entre os paralelos $21^{\circ} 15^{\prime}$ e $21^{\circ} 50^{\prime}$ de latitude sul e os meridianos $44^{\circ} 15^{\prime}$ e $44^{\circ} 45^{\prime}$ de longitude a oeste de Greenwich) e microrregião Campos da Mantiqueira, em Minas Gerais.

O clima da área de estudos é de transição entre Cwa e Cwb, de acordo com a classificação climática de Köppen (ANTUNES, 1986). Os dados climáticos completos mais próximos são encontrados no Município de Lavras ( $21^{\circ} 14$ '06" $\mathrm{S}, 45^{\circ} \mathrm{W}, 918 \mathrm{~m}$ de altitude - normais climatológicas compreendendo o período de 1961 a 1990), onde a temperatura média anual é de $19,4{ }^{\circ} \mathrm{C}$, com média máxima de $28,4{ }^{\circ} \mathrm{C}$ no mês de fevereiro e média mínima de $10,4^{\circ} \mathrm{C}$ no mês de julho. A precipitação média anual é de $1.529,7 \mathrm{~mm}$, com o período de maior precipitação $(83,25 \%)$ compreendido entre os meses de outubro e março (BRASIL, 1992).

Na década de 1950, o local foi utilizado como área de empréstimo para a construção da barragem, tendo sofrido desmatamento e remoção de até $5 \mathrm{~m}$ de perfil do solo. Anteriormente à degradação, a área apresentava uma declividade em torno de $15 \%$ e cobertura vegetal de porte arbóreo. Durante mais de 30 anos, nenhuma medida para a recuperação da área foi tomada. A rala cobertura vegetal que se desenvolveu era formada por espécies herbáceas, pouco eficientes na proteção do solo. Em 1991, o local foi novamente utilizado como área de empréstimo, visando à construção de uma ensecadeira para reparos no piso de concreto abaixo dos vertedouros. Nessa operação foram retirados cerca de $40.000 \mathrm{~m}^{3}$ de terra, tornando a área ainda menos favorável aos processos naturais de estabelecimento de cobertura vegetal, gerando, assim, a necessidade de intervenção antrópica para a sua recuperação. No mês de março de 1992, foram realizados os procedimentos para a recuperação da área. Foram construídos terraços em nível, e a área foi totalmente subsolada a $30-60 \mathrm{~cm}$ de profundidade, em linhas em nível a cada 1,5 m. Posteriormente, efetuou-se o sulcamento, também em nível, a cada 1,5 m, intercalado às linhas de subsolagem. O plantio foi realizado no espaçamento de 1,5 x 3,0 $\mathrm{m}$, em qüincôncio, com base nos princípios de sucessão secundária, alternando linhas de espécies pioneiras com linhas de espécies climácicas. A adubação utilizada foi de $250 \mathrm{~g} /$ cova de superfosfato simples. Foi efetuada uma única adubação em cobertura, aos dois anos, com 150 g/planta de NPK 10:30:10 (DAVIDE e FARIA, 1997).

R. Árvore, Viçosa-MG, v.31, n.1, p.177-185, 2007 


\subsection{Método de amostragem}

A amostragem das espécies arbóreas foi realizada por meio de três transectos de $15 \mathrm{~m}$ de largura e comprimento variável. Os transectos se estenderam da margem do rio até a área de topo, englobando todo o gradiente topográfico (Figura 1).

Os transectos se distanciam entre si em aproximadamente $20 \mathrm{~m}$. Foram medidas todas as plantas do estrato arbóreo, oriundas tanto do plantio quanto de regeneração natural. Esses transectos foram divididos em parcelas de $12 \times 15 \mathrm{~m}$, para controle do gradiente topográfico. No primeiro transecto, foram demarcadas 12 parcelas (144 m de comprimento), no segundo 10 parcelas (120 m de comprimento) e no terceiro 11 parcelas (132 $\mathrm{m}$ de comprimento). Foram incluídos no estrato arbóreo todos os indivíduos com DAP (diâmetro à altura do peito) maior que 5 $\mathrm{cm}$. Todos esses indivíduos foram marcados com plaquetas de alumínio numeradas. A altura foi estimada e a CAP (circunferência à altura do peito), medida com o auxílio de uma trena e, posteriormente, convertida em DAP.

A resistência mecânica do solo à penetração foi determinada em novembro de 2005, utilizandose o penetrômetro de impacto modelo IAA/ PLANALSUCAR-STOLF, segundo a metodologia preconizada por Stolf et al. (1983). Os locais avaliados foram quatro em cada transecto, seguindo-se o gradiente topográfico, até uma profundidade de 60 $\mathrm{cm}$. Os cálculos foram realizados com o apoio do programa PENETRON' (STOLF, 1991), tendo os valores, obtidos em $\mathrm{kgf} / \mathrm{cm}^{2}$, sido convertidos em MPa, multiplicando-se pela constante 0,098.

O levantamento foi realizado em fevereiro de 2005, aos 155 meses após o plantio. Foi utilizado para cálculo dos incrementos relativos um levantamento realizado por Davide e Faria (1997), que foi realizado apenas para algumas espécies, aos 58 meses após o plantio. O incremento médio anual (IMA) das espécies foi calculado, dividindo-se a altura e o DAP médios por 12,9 anos (155 meses). O incremento relativo foi calculado pela média de crescimento em altura e DAP no período entre 58 e 155 meses, em relação à média de crescimento nos primeiros 58 meses após o plantio.

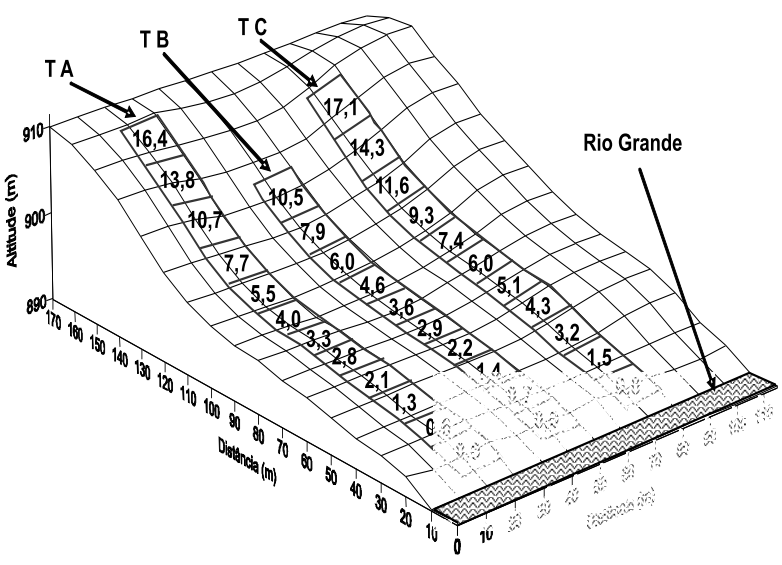

Figura 1 - Perfil topográfico da área do levantamento a jusante da Barragem de Camargos, com as cotas médias das parcelas em $\mathrm{m}$. Foi admitido que a primeira parcela de cada transecto possui cota zero.

Figure 1 - Topography of the survey area downstream of the Camargos dam with average topographic levels of the parcels in meters. It was assumed that the first parcel of each transect has topographic level at zero.

Para verificar o efeito do gradiente topográfico e da resistência do solo à penetração sobre o crescimento em altura e DAP e sobre a densidade de plantas, foi realizada uma análise de regressão, utilizando-se o programa $S A S$, pelo método Backward. Segundo Scolforo (2005), esse método consiste em analisar a regressão contendo o maior número de variáveis desejado ou possível e, posteriormente, promover a redução do modelo (número de variáveis), através da comparação do teste F parcial de cada variável com o teste $\mathrm{F}$, de tabela. Os passos básicos para a construção de modelo a partir desse método consistem em: ajustar a equação de regressão contendo todas as variáveis propostas; calcular o valor parcial de F para todas as varáveis envolvidas no ajuste; a variável que apresentar o menor valor de $\mathrm{F}$ parcial $\left(\mathrm{F}_{\mathrm{p}}\right)$ deve ter esse valor comparado com $\mathrm{F}$, de tabela $\left(\mathrm{F}_{\mathrm{t}}\right)$; se $\mathrm{F}_{\mathrm{p}}<\mathrm{F}_{\mathrm{t}}$, remover essa variável do modelo e ajustar nova regressão sem ela; repetir o procedimento a partir do segundo passo; se $\mathrm{F}_{\mathrm{p}}>\mathrm{F}_{\mathrm{t}}$, então o modelo ajustado já é o modelo definitivo.

No presente trabalho, além das variáveis independentes cota e resistência do solo à penetração de 0 a $30 \mathrm{~cm}$ e de 30 a $60 \mathrm{~cm}$, foram criadas algumas outras variáveis pela combinação destas.

R. Árvore, Viçosa-MG, v.31, n.1, p.177-185, 2007 


\section{RESULTADOS E DISCUSSÃO}

\subsection{Crescimento em altura e diâmetro}

Os valores de atura média, DAP médio, incremento médio anual em altura e em diâmetro, aos 155 meses após o plantio, são apresentados no Quadro 1 .

Verificou-se que todas as espécies que apresentaram os 10 maiores DAP médios e oito das que exibiram as 10 maiores alturas médias pertenciam à família Fabaceae, apesar de que apenas $51 \%$ das espécies plantadas pertenceram a essa família. Isso reforça a tese de que espécies dessa família são fundamentais para a recuperação de áreas degradadas, pois apresentam rápido crescimento em ambientes adversos devido, principalmente, à capacidade de se associarem a fungos micorrízicos e bactérias do gênero Rhizobium (CHADA et al., 2004).

Quadro 1 - Grupo ecológico, altura média, DAP médio, incremento médio anual em altura e DAP das espécies do estrato arbóreo (DAP $\geq 5 \mathrm{~cm}$ ) na área de empréstimo da Usina Hidrelétrica da Camargos, aos 155 meses de idade

Table 1 -Ecological group, average height, average DBH, average yearly increment in height and DBH of the tree stratum species $(D B H \geq 5 \mathrm{~cm})$, at 155 months of age in the area degraded for the construction of the dam of Camargos Hydroelectric Plant

\begin{tabular}{|c|c|c|c|c|c|}
\hline Espécie & $\begin{array}{c}\text { Grupo } \\
\text { ecológico }\end{array}$ & $\begin{array}{c}\text { Altura } \\
\text { média }(\mathrm{m})\end{array}$ & $\begin{array}{c}\text { DAP } \\
\text { médio }(\mathrm{cm})\end{array}$ & $\begin{array}{l}\text { IMA H } \\
\text { (m/ano) }\end{array}$ & $\begin{array}{l}\text { IMA DAP } \\
(\mathrm{cm} / \text { ano })\end{array}$ \\
\hline Piptadenia gonoacantha (Mart.) Macbr. & $\mathrm{P}$ & 13,9 & 34,4 & 1,1 & 2,7 \\
\hline Inga affinis DC. & CL & 13,5 & 34,4 & 1,0 & 2,7 \\
\hline Clitoria fairchildiana Howard. & CL & 12,0 & 25,5 & 0,9 & 2,0 \\
\hline Machaerium villosum Vogel. & CL & 12,0 & 28,7 & 0,9 & 2,2 \\
\hline Anadenanthera colubrina (Vell.) Brenan. & $\mathrm{P}$ & 10,8 & 18,1 & 0,8 & 1,4 \\
\hline Acacia mangium Willd. & $\mathrm{P}$ & 8,8 & 17,8 & 0,7 & 1,4 \\
\hline Cecropia pachystachya Trec. & $\mathrm{P}$ & 8,7 & 9,6 & 0,7 & 0,7 \\
\hline Trema micrantha (L.) Blume. & $\mathrm{P}$ & 8,6 & 13,9 & 0,7 & 1,1 \\
\hline Erythrina falcata Benth. & CL & 8,4 & 18,6 & 0,6 & 1,4 \\
\hline Acacia auriculiformis A. Cunn. ex Benth & $\mathrm{P}$ & 7,9 & 23,4 & 0,6 & 1,8 \\
\hline Maclura tinctoria (L.) D. Don ex Steud. & $\mathrm{P}$ & 7,8 & 10,0 & 0,6 & 1,2 \\
\hline Mimosa caesalpiniaefolia Benth. & $\mathrm{P}$ & 7,8 & 16,1 & 0,6 & 0,8 \\
\hline Mimosa bimucronata (DC.) Kuntze. & $\mathrm{P}$ & 7,6 & 12,8 & 0,6 & 0,8 \\
\hline Ficus sp & CL & 7,6 & 9,7 & 0,6 & 0,8 \\
\hline Senna multijuga (LC Rich.) Irwin \& Barn. & $\mathrm{P}$ & 7,6 & 10,7 & 0,6 & 1,0 \\
\hline Enterolobium contortisiliquиm (Vell.) Morong. & CL & 7,5 & 34,3 & 0,6 & 2,7 \\
\hline Rapanea ferruginea (Ruiz \& Pav.) Mez. & $\mathrm{P}$ & 7,3 & 6,8 & 0,6 & 0,5 \\
\hline Alchornea triplinervia (Spreng.) M.Arg.* & CL & 7,0 & 7,5 & - & - \\
\hline Platycyamus regnellii Benth. & CL & 7,0 & 8,1 & 0,5 & 0,6 \\
\hline Inga marginata Willd. & CS & 7,0 & 17,0 & 0,5 & 1,3 \\
\hline Cedrela fissilis Vell. & CL & 7,0 & 10,7 & 0,5 & 0,8 \\
\hline Tapirira guianensis Aubl. & $\mathrm{P}$ & 7,0 & 7,2 & 0,5 & 0,6 \\
\hline Muntingia calabura $\mathrm{L}$. & $\mathrm{P}$ & 7,0 & 12,3 & 0,5 & 1,0 \\
\hline Peltophorum dubium (Spreng.) Taub. & CL & 6,9 & 9,0 & 0,5 & 0,7 \\
\hline Myrsine umbellata Mart. & CL & 6,8 & 7,2 & 0,5 & 0,6 \\
\hline Croton urucurana Baill. & $\mathrm{P}$ & 6,6 & 8,6 & 0,5 & 0,7 \\
\hline Lafoensia pacari St. Hil.* & CL & 6,0 & 6,3 & - & - \\
\hline Copaifera langsdorffii Desf. & $\mathrm{CS}$ & 6,0 & 8,6 & 0,5 & 0,7 \\
\hline Syzygium jambolanum (Lam.) DC. & CL & 6,0 & 12,2 & 0,5 & 0,9 \\
\hline Senna spectabilis (DC.) Irwin \& Barn. & $\mathrm{P}$ & 5,9 & 8,5 & 0,5 & 0,7 \\
\hline Senna macranthera (Collad.) Irwin \& Barn. & $\mathrm{P}$ & 5,8 & 7,7 & 0,4 & 0,6 \\
\hline Lithraea molleoides (Vell.) Engl. & $\mathrm{P}$ & 5,7 & 8,1 & 0,4 & 0,6 \\
\hline Nectandra nitidula Nees \& Mart.* & $\mathrm{P}$ & 5,3 & 5,5 & - & - \\
\hline Schinus terebinthifolius Raddi. & $\mathrm{P}$ & 5,2 & 10,3 & 0,4 & 0,8 \\
\hline Vernonia polyanthes Less.* & $\mathrm{P}$ & 5,0 & 7,3 & - & - \\
\hline Sebastiania schottiana Müll.Arg. & $\mathrm{P}$ & 5,0 & 6,2 & 0,4 & 0,6 \\
\hline Psidium guajava $\mathrm{L}$. & CL & 5,0 & 6,6 & 0,4 & 0,5 \\
\hline Eriobotrya japonica (Thunb.) Lindl. & CS & 4,9 & 8,0 & 0,4 & 0,6 \\
\hline Tibouchina candolleana (Mart. ex DC.) Cogn.* & CL & 4,9 & 7,6 & - & - \\
\hline Zanthoxylum rhoifolium Lam.* & CL & 4,5 & 7,6 & - & - \\
\hline
\end{tabular}

* Espécies provenientes de regeneração natural

R. Árvore, Viçosa-MG, v.31, n.1, p.177-185, 2007 
Foram encontrados, no estrato arbóreo do maciço florestal (DAP $\geq 5 \mathrm{~cm}$ ), indivíduos de Alchornea triplinervia, Nectandra nitidula, Lafoensia pacari, Tibouchina candolleana, Vernonia polyanthes e Zanthoxylum rhoifolium. Essas espécies não foram plantadas no processo de recuperação, sendo, portanto, provenientes da regeneração natural. Pelo porte apresentado, essas espécies podem ser consideradas como boas colonizadoras de ambiente degradado e, portanto, devem ser selecionadas para plantio nessas áreas.

Apesar de espécies exóticas como Acacia mangium e Acacia auriculiformis serem consideradas ideais para a recuperação de áreas degradadas (PIO CORRÊA, 1984; FERREIRA et al., 1990; DIAS et al., 1991), elas tiveram seu crescimento em altura e DAP superado por algumas espécies nativas da região, com alguns indivíduos de Piptadenia gonoacantha e Anadenanthera colubrina atingindo alturas acima de $20 \mathrm{~m}$. Apesar de não ter se destacado no crescimento em altura, Enterolobium contortisiliquum obteve o terceiro maior DAP médio, concordando com a afirmação de Carvalho (1994) de que seu crescimento em diâmetro é rápido.

Com relação às espécies que apresentaram os 10 maiores incrementos médios anuais (IMA) em altura e diâmetro no presente levantamento (155 meses) (Quadro 1) e na avaliação realizada por Davide e Faria (1997), na mesma área, aos 58 meses (Quadro 2), Piptadenia gonoacantha e Inga affinis, apesar de terem diminuído o seu ritmo de crescimento em altura, destacaram-se em relação às demais. Acacia auriculiformis, que foi a espécie que apresentou o maior IMA em altura, na avaliação realizada por Davide e Faria (1997), teve seu ritmo de crescimento reduzido, apresentando um valor de IMA, aos 155 meses, de 1/3 em relação ao anterior. Cecropia pachystachya e Trema micrantha também apresentaram redução do IMA em altura aos 155 meses, com valores de aproximadamente a metade do IMA aos 58 meses, confirmando a redução no seu ritmo de crescimento após oito anos, reforçando o pioneirismo dessas espécies, que tendem a atingir o seu pico de crescimento mais cedo que as climácicas.

No incremento em diâmetro houve redução na participação de pioneiras de oito para quatro, comparandose com a primeira avaliação, o que pode ser considerado normal em um estágio mais avançado de desenvolvimento das espécies do povoamento. Piptadenia gonoacantha e Inga affinis aumentaram o IMA em diâmetro em relação aos 58 meses. Acacia auriculiformis, apesar de continuar entre os 10 maiores IMA em DAP, apresentou redução no ritmo de crescimento. As espécies Enterolobium contortisiliquum, Machaerium villosum, Clitoria fairchildiana, Erythrina falcata, Anadenanthera colubrina e Acacia mangium não foram avaliadas por Davide e Faria (1997) aos 58 meses de idade.

O incremento relativo em altura e diâmetro das espécies que foram avaliadas aos 58 meses por Davide e Faria (1997) e também aos 155 meses, compreendendo um período de 97 meses, é apresentado no Quadro 3.

Quadro 2 - Incremento médio anual em altura e DAP das espécies avaliadas por Davide e Faria (1997) aos 58 meses de idade, na área de empréstimo da Usina Hidrelétrica de Camargos

Table 2 - Average yearly increment in height and DBH of the species evaluated by Davide e Faria (1997), at 58 months of age, in the area degraded for the construction of the dam of Camargos Hydroelectric Plant

\begin{tabular}{|c|c|c|c|}
\hline Espécie & $\begin{array}{l}\text { Grupo } \\
\text { cológico }\end{array}$ & $\begin{array}{c}\text { IMA } \\
\text { altura }\end{array}$ & $\begin{array}{l}\text { IMA } \\
\text { DAP } \\
\end{array}$ \\
\hline $\begin{array}{l}\text { Acacia auriculiformis } \\
\text { A. Cunn. ex Benth }\end{array}$ & $\mathrm{P}$ & 1,8 & 2,7 \\
\hline $\begin{array}{l}\text { Piptadenia gonoacantha } \\
\text { (Mart.) Macbr. }\end{array}$ & $\mathrm{P}$ & 1,6 & 2,4 \\
\hline Inga affinis DC. & $\mathrm{CL}$ & 1,5 & 2,0 \\
\hline Cecropia pachystachya Trec. & . $\mathrm{P}$ & 1,3 & 1,7 \\
\hline Muntingia calabura L. & $\mathrm{P}$ & 1,2 & 1,7 \\
\hline Croton urucurana Baill. & $\mathrm{P}$ & 1,1 & 1,5 \\
\hline Trema micrantha (L.) Blume. & . $P$ & 1,1 & 1,6 \\
\hline $\begin{array}{l}\text { Senna multijuga (LC Rich.) } \\
\text { Irwin \& Barn. }\end{array}$ & $\mathrm{P}$ & 1,0 & 1,4 \\
\hline Schinus terebinthifolius Raddi. & li. $\mathrm{P}$ & 0,9 & 1,0 \\
\hline $\begin{array}{l}\text { Senna macranthera (Collad.) } \\
\text { Irwin \& Barn. }\end{array}$ & $P$ & 0,9 & 1,0 \\
\hline $\begin{array}{l}\text { Senna spectabilis (DC.) } \\
\text { Irwin \& Barn. }\end{array}$ & $\mathrm{P}$ & 0,9 & 0,9 \\
\hline $\begin{array}{l}\text { Lithraea molleoides } \\
\text { (Vell.) Engl. }\end{array}$ & $\mathrm{P}$ & 0,8 & 0,8 \\
\hline $\begin{array}{l}\text { Peltophorum dubium } \\
\text { (Spreng.) Taub. }\end{array}$ & CL & 0,8 & 1,0 \\
\hline Psidium guajava $\mathrm{L}$. & $\mathrm{CL}$ & 0,8 & 0,7 \\
\hline $\begin{array}{l}\text { Syzygium jambolanum } \\
\text { (Lam.) DC. }\end{array}$ & CL & 0,8 & 1,0 \\
\hline Ficus sp & CL & 0,7 & 0,7 \\
\hline Inga marginata Willd & CS & 0,6 & 0,6 \\
\hline $\begin{array}{l}\text { Sebastiania schottiana } \\
\text { Müll.Arg. }\end{array}$ & $\mathrm{P}$ & 0,6 & 0,5 \\
\hline Tapirira guianensis Aubl. & $\mathrm{P}$ & 0,6 & 0,6 \\
\hline Cedrela fissilis Vell. & CL & 0,5 & 0,8 \\
\hline Copaifera langsdorffii Desf. & $\mathrm{CS}$ & 0,3 & 0,2 \\
\hline
\end{tabular}

R. Árvore, Viçosa-MG, v.31, n.1, p.177-185, 2007 
Quadro 3 - Incremento relativo (IR) em altura (H) e DAP entre o primeiro período de crescimento (58 meses) e o segundo (58-155 meses) das espécies plantadas no processo de recuperação

Table 3 - Increment (IR) in height $(H)$ and DBH between the first period of growth (58 months) and the second (58-155 months), of the species planted on the land restoration

\begin{tabular}{|c|c|c|c|}
\hline Espécie & $\begin{array}{l}\text { Grupo } \\
\text { ecológico }\end{array}$ & $\begin{array}{c}\text { IR } \\
\mathrm{H}(\%)\end{array}$ & $\begin{array}{c}\text { IR } \\
\text { DAP }(\%)\end{array}$ \\
\hline$\overline{\text { Copaifera langsdorffii Desf. }}$ & $\mathrm{CS}$ & 308,2 & 756,3 \\
\hline Inga marginata Willd & CS & 153,6 & 448,4 \\
\hline Cedrela fissilis Vell. & $\mathrm{CL}$ & 152,0 & 137,1 \\
\hline Tapirira guianensis Aubl. & $\mathrm{P}$ & 146,5 & 167,6 \\
\hline Ficus sp & $\mathrm{CL}$ & 122,9 & 202,5 \\
\hline Inga affinis DC. & CL & 81,0 & 240,3 \\
\hline $\begin{array}{l}\text { Piptadenia gonoacantha } \\
\text { (Mart.) Macbr. }\end{array}$ & $\mathrm{P}$ & 72,8 & 182,1 \\
\hline $\begin{array}{l}\text { Peltophorum dubium } \\
\text { (Spreng.) Taub. }\end{array}$ & $\mathrm{CL}$ & 68,4 & 96,4 \\
\hline $\begin{array}{l}\text { Sebastiania schottiana } \\
\text { Müll.Arg. }\end{array}$ & $\mathrm{P}$ & 65,6 & 167,8 \\
\hline Trema micrantha (L.) Blume. & e. $P$ & 58,4 & 77,8 \\
\hline $\begin{array}{l}\text { Senna multijuga (LC Rich.) } \\
\text { Irwin \& Barn. }\end{array}$ & $\mathrm{P}$ & 51,7 & 54,7 \\
\hline $\begin{array}{l}\text { Lithraea molleoides } \\
\text { (Vell.) Engl. }\end{array}$ & $P$ & 49,8 & 117,5 \\
\hline $\begin{array}{l}\text { Syzygium jambolanum } \\
\text { (Lam.) DC. }\end{array}$ & $\mathrm{CL}$ & 49,5 & 140,1 \\
\hline $\begin{array}{l}\text { Senna spectabilis (DC.) } \\
\text { Irwin \& Barn. }\end{array}$ & $\mathrm{P}$ & 42,9 & 102,9 \\
\hline Cecropia pachystachya Trec. & c. $\mathrm{P}$ & 32,5 & 15,3 \\
\hline Psidium guajava $\mathrm{L}$. & CL & 30,6 & 106,4 \\
\hline $\begin{array}{l}\text { Senna macranthera (Collad.) } \\
\text { Irwin \& Barn. }\end{array}$ & .) $\mathrm{P}$ & 24,0 & 51,8 \\
\hline Muntingia calabura L. & $\mathrm{P}$ & 18,4 & 47,9 \\
\hline Croton urucurana Baill. & $\mathrm{P}$ & 16,2 & 13,6 \\
\hline Schinus terebinthifolius Raddi. & di. $P$ & 16,2 & 106,8 \\
\hline $\begin{array}{l}\text { Acacia auriculiformis A. } \\
\text { Cunn. ex Benth }\end{array}$ & $\mathrm{P}$ & $-11,6$ & 73,1 \\
\hline
\end{tabular}

Entre as espécies que apresentaram os 10 maiores incrementos relativos em altura e diâmetro nesse período, apenas quatro foram classificadas como pioneiras. Esse fato, aliado aos dois maiores incrementos relativos em altura e diâmetro apresentados por Copaifera langsdorffii e Inga marginata, que são espécies climácicas tolerantes à sombra, características de florestas maduras, indica que o povoamento está se encaminhando para uma fase mais avançada de sucessão, em que as pioneiras já promovem uma condição de sombreamento que permite o desenvolvimento de espécies climácicas.

A espécie Acacia auriculiformis apresentou uma redução em altura de $11,55 \%$, no referido período. Esse decréscimo na altura é explicado pelo fato de que a maioria dos indivíduos dessa espécie apresentava morte dos ponteiros, que foram quebrados pelo vento. Esse pioneirismo acentuado desta espécie pode ter sido causado pela alta degradação da área e por ela não se encontrar em seu ambiente original.

\subsection{Desempenho em função do gradiente topográfico e da resistência do solo à penetração}

Os modelos de regressão que melhor estimaram as variáveis dependentes densidade de plantas, altura média e DAP médio, em função das variáveis independentes cota e resistência do solo à penetração de 0-30 cm e de 30-60 cm e da combinação destas, são apresentados a seguir:

$$
\begin{aligned}
& \text { dên }=387,70433+803,20206 c+43,67999 c^{2}-1,73572 c^{3}-227,98858 \\
& c \times r 30-5,79185 c \times r 60+\frac{1978,11866}{r 30}-1150,65448 \frac{c}{r 30} \\
& \mathrm{R}^{2}=99,37 \% \\
& \hat{h}=6,79754-0,1953 c+0,09132 c \times r 60-\frac{13,49105}{r 30}+\frac{14,61457}{r 60} \\
& \mathrm{R}^{2}=94,31 \% \\
& D \hat{A} P=25,02376+0,52218 c^{2}-0,02409 c^{3}-1,40430 c \times r 30+ \\
& +0,41535 c \times r 60-\frac{31,42274}{r 30}-9,06581 \frac{c}{r 30}+9,66376 \frac{c}{r 60} \\
& \mathrm{R}^{2}=99,60 \%
\end{aligned}
$$

em que:

$$
\text { dên = densidade de plantas/ha; }
$$

$\hat{h}=$ altura;

$D \hat{A} P=$ diâmetro a altura do peito;

$\mathrm{c}=\operatorname{cota}$

$\mathrm{c}^{2}=(\operatorname{cota})^{2}$

$\mathrm{c}^{3}=(\operatorname{cota})^{3}$;

r30 = resistência do solo à penetração na profundidade de $0-30 \mathrm{~cm}$; e

r60 = resistência do solo à penetração na profundidade de $30-60 \mathrm{~cm}$.

Verificou-se que houve efeito das variáveis cotas e resistência do solo à penetração, confirmado pelos modelos ajustados, com altos valores de $\mathrm{R}^{2}$.

A densidade, altura média e o DAP médio das plantas em função do gradiente topográfico, nas diferentes parcelas, são mostrados na Figura 2. 
As menores densidades de plantas encontradas nas parcelas com maior resistência do solo à penetração indicam que a mortalidade das mudas plantadas foi maior nessas áreas, resultando em menor número de plantas estabelecidas. Essas parcelas estão localizadas na parte média do gradiente topográfico (Figuras 1 e $2^{\mathrm{a}}$ e Quadro 4.)

O maior crescimento em altura foi verificado nas plantas localizadas nas três primeiras parcelas a partir da margem, enquanto os menores crescimentos em altura foram obtidos na porção média do gradiente topográfico (Figura 2B).

As parcelas onde foram encontradas as menores alturas médias, cota 4,0 m no transecto A e cota 2,9 $\mathrm{m}$ no transecto B (Figura $2 \mathrm{~B}$ ), foram justamente aquelas que apresentaram as maiores resistências à penetração em profundidades abaixo de $30 \mathrm{~cm}$, nas parcelas avaliadas (Quadro 4).
Quadro 4 - Medias de resistência do solo à penetração, em MPa, nas profundidades de 0 a $30 \mathrm{~cm}$ e de 30 a $60 \mathrm{~cm}$, nas parcelas amostradas

Table 4 - Means of soil penetration resistance, in $M P a$, at 0 to $30 \mathrm{~cm}$ and 30 to $60 \mathrm{~cm}$ depths, of the sampled parcels

\begin{tabular}{cccc}
\hline Transecto & Cota $(\mathrm{m})$ & $\begin{array}{c}\mathrm{R} 0-30 \mathrm{~cm} \\
(\mathrm{MPa})\end{array}$ & $\begin{array}{c}\text { R } 30-60 \mathrm{~cm} \\
(\mathrm{MPa})\end{array}$ \\
\hline A & 0,0 & 3,5 & 2,7 \\
A & 4,0 & 2,3 & 7,3 \\
A & 7,7 & 2,6 & 6,4 \\
A & 16,4 & 1,6 & 1,8 \\
B & 0,0 & 2,1 & 3,0 \\
B & 2,9 & 2,2 & 13,6 \\
B & 6,0 & 1,7 & 1,6 \\
B & 10,5 & 2,7 & 5,4 \\
C & 4,3 & 3,0 & 5,6 \\
C & 11,6 & 2,4 & 4,4 \\
C & 17,1 & 2,5 & 2,2 \\
\hline
\end{tabular}
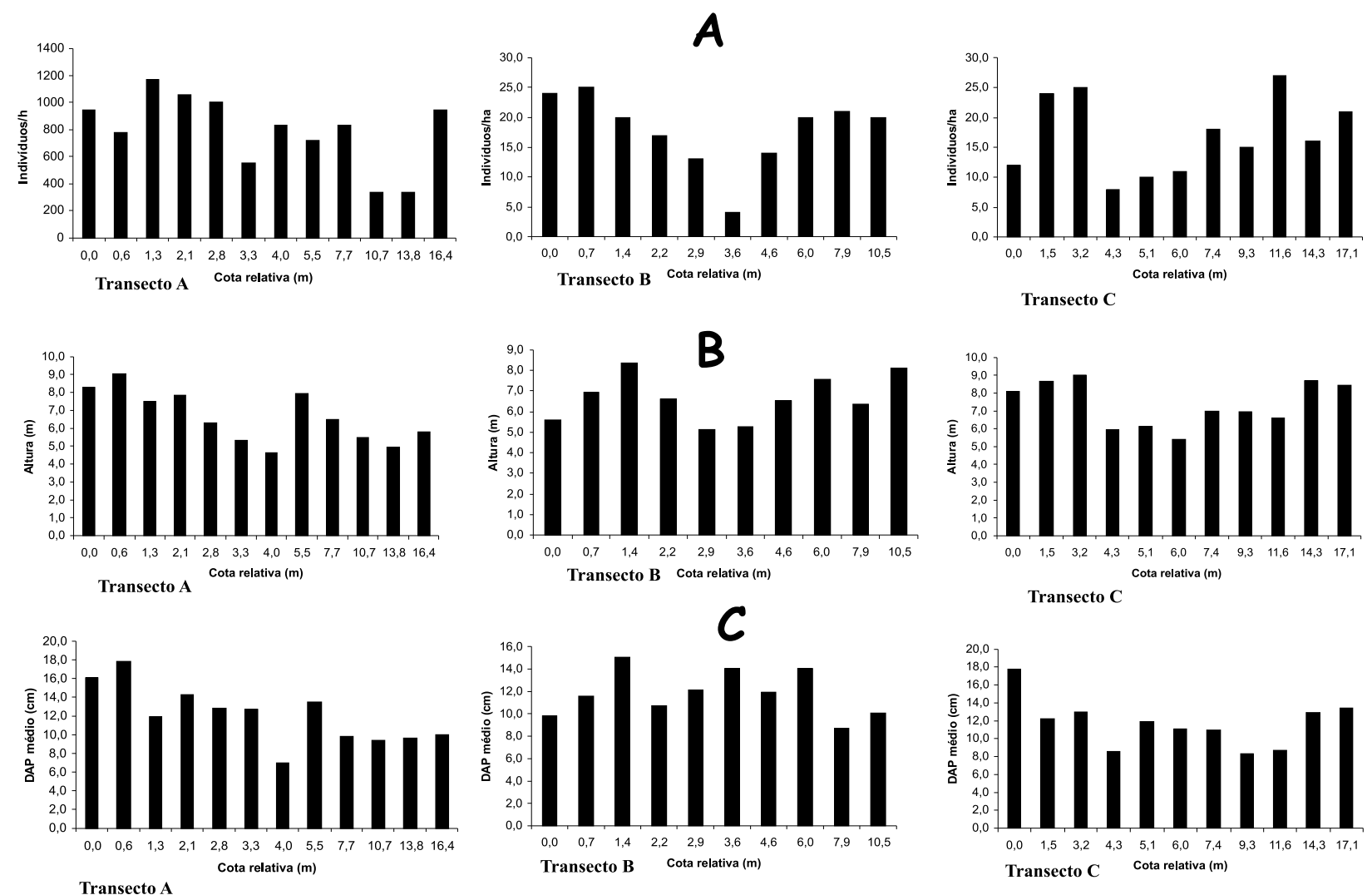

Figura 2 - Densidade (A), altura (B) e DAP (C) médios dos indivíduos do estrato arbóreo (DAP=5 cm), em função da variação do gradiente topográfico.

Figure $2-$ Mean density $(A)$, height $(B)$ and $D B H(C)$ of the trees with $D B H=5 \mathrm{~cm}$, as a function of the topographic gradient. 
Com relação ao crescimento em DAP, verificouse que os maiores valores foram observados nos locais onde também ocorreram as maiores alturas. (Figura 2BC). Assim como se verificou no crescimento em altura, nos locais com alta resistência do solo à penetração o crescimento em DAP foi afetado negativamente (Figura 2C e Quadro 4).

Esses fatos indicam que a existência de camadas muito compactadas, na profundidade de 30 a $60 \mathrm{~cm}$, causou efeito negativo no estabelecimento e crescimento das plantas, sendo muito evidente a partir de 7,3 $\mathrm{MPa}$, valor considerado muito alto, de acordo com a classificação de Soil Survey Staff (1993).

\section{CONCLUSÕES}

Em relação à dinâmica de crescimento das espécies plantadas, foi verificado aumento no ritmo de crescimento das espécies clímax após 58 meses, enquanto a maioria das espécies pioneiras apresentou redução no ritmo de crescimento nesse mesmo período, com algumas espécies, como Acacia mangium, A. auriculiformis e Croton urucurana, mostrando avançados sinais de senescência.

O crescimento das espécies plantadas foi afetado pela presença de camadas restritivas ao crescimento radicular e pelo gradiente topográfico. O crescimento de algumas espécies nativas, como Piptadenia gonoacantha e Inga affinis, superou o de espécies exóticas recomendadas para a recuperação de áreas degradadas, como Acacia mangium e A. auriculiformis.

\section{AGRADECIMENTOS}

Ao professor Daniel Furtado Ferreira, pelo auxílio na análise estatística dos dados; à Companhia Energética de Minas Gerais - CEMIG, pelo financiamento do projeto P \&D 039 através do convênio UFLA/CEMIG/ANEEL e à CAPES pela concessão da bolsa de pós-graduação ao primeiro autor.

\section{REFERÊNCIAS}

ANTUNES, F. Z. Caracterização climática do Estado de Minas Gerais. Informe Agropecuário, v.12, n.138, p.9-13, 1986.

ARATO, H. D.; MARTINS, S. V.; FERRARI, S. H. S. Produção e decomposição de serrapilheira em um sistema agroflorestal implantado para recuperação de área degradada em Viçosa-MG. Revista Árvore, v.27, n.5, p.715-721, 2003.

R. Árvore, Viçosa-MG, v.31, n.1, p.177-185, 2007
BRASIL. Ministério da Agricultura e Reforma Agrária. Departamento Nacional de Meteorologia. Normais climatológicas (1961-1990). Brasília: 1992. 84p.

CARPANEZZI, A. A. et al. Espécies pioneiras para recuperação de áreas degradadas: a observação de laboratórios naturais. In: CONGRESSO FLORESTAL BRASILEIRO, 6., Campos do Jordão. Anais... São Paulo: Sociedade Brasileira de Silvicultura, 1990. v.3.

CARVALHO, P. E. R. Espécies florestais brasileiras: recomendações silviculturais, potencialidades e uso da madeira. Colombo: Embrapa-CNPF/Brasília: Embrapa - SPI, 1994. 640p.

CHADA, S. S.; CAMPELLO, E. F. C.; FARIA, S. M. Sucessão vegetal em uma encosta reflorestada com leguminosas arbóreas em Angra dos Reis, RJ. Revista Árvore, v.28, n.6, p.801-809, 2004.

DAVIDE, A. C.; FARIA, J. M. R. Revegetação de área de empréstimo da Usina Hidrelétrica de Camargos (CEMIG). In: SIMPÓSIO NACIONAL DE RECUPERAÇÃO DE ÁREAS DEGRADADAS, 3., 1997, Ouro Preto. Trabalhos voluntários... Viçosa, MG: SOBRADE; UFV/ DPS/DEF, 1997. p. 462-473.

DIAS, E. D.; ALVARES, V. H.; BRIENZA JÚNIOR, S. Formação de mudas de Acacia mangium. Resposta a nitrogênio e potássio. Revista Árvore, v.15, n.1, p.11-22, 1991.

DIAS, L. E.; GRIFFITH, J. J. Conceituação e caracterização de áreas degradadas. In: DIAS, L. E.; MELLO, J. W. V. (Ed.). Recuperação de áreas degradadas. Viçosa, MG: Universidade Federal de Viçosa/Departamento de Solos/ Sociedade Brasileira de Recuperação de Áreas Degradadas, 1998. p.1-7.

FERREIRA, C. A. et al. Acacia mangium: uma nova opção para reflorestamento. In: CONGRESSO FLORESTAL BRASILEIRO, 6 ., 1990, Campos do Jordão. Anais... Campos do Jordão: SBS, 1990. p.564-568. 
FERREIRA, C. A. G. Efeito do uso do solo de horizonte A e do gesso no comportamento de espécies florestais em áreas degradadas pela disposição de resíduo de bauxita. 2001. 124f. Tese (Doutorado em Conservação e Manejo de Recursos)-Universidade Estadual de São Paulo, Rio Claro, 2001.

PIO CORRÊA, M. Dicionário de plantas úteis do Brasil e das exóticas

cultivadas. Brasília: IBAMA, 1984. v.3. p.230-543.

SCOLFORO, J. R. Biometria florestal:

modelos de regressão linear e não linear. Lavras: UFLA/FAEPE, 2005. Parte 1.352p.
SOIL SURVEY STAFF. Soil survey manual. Washington: USDASCS, U.S. Gov, Print. Office, 1993. 437p. (Handbook, 18).

STOLF, R. Teoria e tese experimental de fórmulas de transformação dos dados de penetrômetro de impacto em resistência do solo. Revista Brasileira de Ciência do Solo, v. 15, n.3, p.229-235, 1991.

STOLF, R.; FERNADES, J.; FURLANI NETO, V.

L. Recomendação para o uso do penetrômetro de impacto: modelo IAA/ PLANALSUCAR/STOLF. Piracicaba: 1983. p.1-9. (Série Penetrômetro de Impacto. Boletim Técnico, 1). 
